\title{
Architecting Virality: Information Sharing from Government FB Page to Netizens
}

\author{
Afdallyna Fathiyah Harun, Siti Nuradzarul Aqmaar Adzman, Fauzi Mohd Saman, \\ Saiful Izwan Suliman \\ Universiti Teknologi MARA, Selangor, Malaysia
}

\begin{tabular}{l}
\hline \hline Article Info \\
\hline Article history: \\
Received Sep 24, 2017 \\
Revised Dec 30, 2017 \\
Accepted Jan 18, 2018 \\
\hline
\end{tabular}

Keywords:

Citizen-centricity

Digital content

E-government

Information sharing

Virality

\begin{abstract}
In accordance with e-government initiatives, many ministries in Malaysia have engaged content to public using social media for better two-way communications. However, creating an online presence is not necessarily easy as digital content consumers are often bombarded with information and those that fail to capture information will be rendered uninteresting and irrelevant. This is imperative as for most part, users are in control of where they allocate attention and what they share. Using virality as a context, it is opined that information content that are well-designed will trigger specific information and propel the sharing of that information over the Internet. A study employing FB post categorization and sharing motivations survey was carried out in the context of Ministry of Health Malaysia Facebook page. The findings show that users are inclined towards Infographics with various sharing motivations. The results can be used by Malaysian ministries on how best to design and disseminate information for the benefit of the netizens on social media sites.
\end{abstract}

Copyright (c) 2018 Institute of Advanced Engineering and Science. All rights reserved.

\section{Corresponding Author:}

Afdallyna Fathiyah Harun, Universiti Teknologi MARA, Selangor, Malaysia

Email: afdallyna@tmsk.uitm.edu.my

\section{INTRODUCTION}

A 2014 statistic by e27 website indicated that "Malaysian netizens view social network sites...731 times per person" which infers a powerful opportunity for online content dissemination. In line with citizen's online preference, many government ministries are using social networking sites to engage with netizens [1] enabling a much more interpersonal form of correspondence [2]. However, digital content is at the mercy of the internet population where it is only powerful when it is socially transmitted across the digital community. Content creator can create and release information, but its sustainability and accessibility depend on digital content sharing among recipients [3]. Research has found that digital content sharing is highly driven by emotion and that the relationship between the two is highly complex [4][5]. In the current internet lingo, content that are highly shared are considered viral.

Virality is defined by common consensus as the tendency of an image, video, or piece of information to be circulated rapidly and widely from one Internet user to another. According to [6], the spread of viral phenomenon is regarded as part of the cultural politics of network culture which enables audience to create and spread viral content. Audiences play an active role in "spreading" these content rather than serving as passive carriers of viral media: their choices, investments, agendas, and actions determine what gets valued [7]. Nowadays, all information can be digitized and easily distributed using various Web 2.0 platforms particularly social networks (i.e. Facebook) and micro-blogs (i.e. twitter) allowing the direct communication between authority and netizens [8]. However, government organizations are struggling to get users to share their verified information particularly in combatting the spread of false information. With falsities and truth hard to tell apart and omnipresent, misperception and disregard of verified information 
from official channels may be dismissed. As we thrive to become a digital economy nation, netizens need to be abreast with accurate information. Therefore, there is a need to identify what post-types are utilised by government ministries on social media sites as well as recognizing followers' motivation in sharing the information.

\section{METHOD}

\subsection{Research Setup}

The context of this study is social media sites with a focus on government official Facebook (hereinafter referred to as 'FB') page. This is because it was found that almost a third of the adults get at least some of their news from FB [9]. As health is an issue of high stakes when it comes to misinformation, we have opted to look at Malaysia's government body responsible with citizen's health and wellbeing Kementerian Kesihatan Malaysia (KKM/Ministry of Health Malaysia). Moreover, at the time of this study, statistics by [10] indicated that KKM has the highest number of followers for a Malaysian ministry employing FB as a platform to engage with netizens, with 857,795 followers. Using KKM's FB page, we studied the patterns of information design and 'Share' reactions to posts.

Our study is a small-scale study which took place for four months and observing only one government affiliated FB page. The study was conducted from January to April 2017 where KKM FB page was observed and their followers were given a set of questionnaires. The co-author (NA) of this paper is a follower of KKM FB page and therefore, all entries pertaining to KKM were collected and studied from NA's daily newsfeed.

\subsection{Study A: KKM Facebook Information Design Observation}

To understand FB post-type preferred by users, we first categorised the content available in KKM FB page. This was done in January 2017 in a form of pilot study where every new post from KKM that appeared in NA's FB newsfeed were categorised. The structure of the content is examined by adapting the FB post-type codes used by [11]. From the samples collected, it was found that there were four emerging information patterns in KKM FB page. Following this, we further refined [11] codes for clarity as well as for practical reasons; namely to limit the number of posts included in the analyses to a manageable amount. Description of the codes is available in Table 1.

Table 1. Facebook Post-Type Codes and Description

\begin{tabular}{cc}
\hline Facebook Post-Type & Description \\
\hline News & Articles which contains press release from KKM \\
Infographic & Health management tips in the form of graphical illustration or posters \\
Official Function & Formal functions held by KKM pertaining to ministry's objectives \\
Random Posts & Health related articles which showcase statistics or photos \\
\hline
\end{tabular}

At the time of this study, user response to a FB post can be in the form of 'Like', 'Comment' and 'Share'. 'Like' allows users to show their emotion towards a post while 'Comment' enables users to share their opinion. As the context of this study considers motivations for digital information sharing, we feel the 'Share' feature best represents this. This is because, when the 'Share' feature is clicked, an FB post can be shared with friends, appear in user timeline or shared with specific recipients.

We employed the controlled observation technique where KKM FB page was observed for the last 11 days for the months of February, March and April 2017. We decided to focus on those days as our pilot study showed that some posts were reposted several times within the same month. However, if within those 11 days a repeated post was found, it will still be calculated as a unique entry.

Each KKM entry that appears in NA's timeline is tabulated according to the post-type codes as in Table 1. Screenshots of the posts were kept for referrals and at the end of the month, the posts were revisited to look at the total number of shares. We used this metric to calculate the percentage of likelihood for an FB post-type to be shared. It must be noted that the posts used in this study were available for public view regardless whether one is a follower of the page or otherwise. Also, the data were collected in accordance with Facebook's terms and conditions.

\subsection{Study B: Questionnaire}

To understand users sharing motivation and their perception towards government's FB posts, onehundred questionnaires created using Google Forms were distributed on the $6^{\text {th }}$ of June 2017 to the followers of KKM FB page. Respondents were selected using selective sampling where we recruited users who have shared KKM's post. They were identified by hovering the mouse cursor on the 'Share' status that appeared 
under KKM post that fits into the categories as per Table 1. Selected respondents were contacted through FB messenger and were briefed on the purpose of the questionnaire and given the Google form link (which was made available for two weeks).

The questionnaire comprised three parts; (i) demographic information, (ii) information sharing preference, and (iii) information perception. The questions asked in the questionnaire made use of closeended format and were designed based on readings from the literature pertaining to information sharing behaviour and information perception.

\subsection{Statistical Analyses}

Descriptive statistics were generated for each post-type where we calculated post-type frequency and the total number of shares. This was similarly done on the questionnaire data to see the data distribution of information preference and sharing motivations. The core idea here is to demonstrate that information design as well as information usefulness affects sharing motivations.

\section{RESULTS AND DISCUSSION}

\subsection{Information Design and 'Share' Reactions in KKM FB Page (Study A)}

One hundred posts were collected from KKM FB page during the observation period that fits into the post-type criteria as tabulated in Table 1. Table 2 summarises the post-type distribution of the collected posts. It was found that KKM FB page is rather active with an average of three posts per day. Post-type wise, there was an average of 1.15 News, 0.73 Infographics, 0.52 Official Function and 0.67 Random Posts for the observed 33 days. From the results, it can be inferred that KKM use News-type posts as the main information delivery to netizens.

There was a total of 21,238 post shares during the observation period. Different post-types project different 'Share' reaction but in a glance, every single posting at KKM FB page is at least shared once. Infographics received the most number of shares with an average of 466.25 shares per post $(52.69 \%$ from total shares). The least favoured post-type to share is Official Functions with only 75.88 shares per post (6.07\% from total share). KKM's main medium for information delivery which is News post-type scored 108.82 share average (19.47\% from total share). An interesting observation here is despite Infographics being the second type of post utilized by KKM to deliver information to the netizens, the number of share average far exceed the other post-types with more than $50 \%$ holding value of total shares. A further investigation further testifies to this where the highest number of total shares for News is 2,721 while for Infographic it is 8,539 despite News posts having more entries. From these data, however, it is not possible to have a simplistic view on type of information design preference as each post-type did not have a consistent sharing pattern. For example, in February, Infographics has the highest number of post share but in March and April, it was News. Nonetheless, Infographics seems more favoured proven with the highest recorded number of shares, highest value of sharing average and still comparatively preferred even at the low side of the equation.

Table 2. Post-Type Distribution Summary

\begin{tabular}{llllll}
\hline Post-Type & Month & Total Post & $\begin{array}{l}\text { Shares for all Post } \\
\text { Combined }\end{array}$ & $\begin{array}{l}\text { Lowest Number of } \\
\text { Post Share }\end{array}$ & $\begin{array}{l}\text { Highest Number of } \\
\text { Post Share }\end{array}$ \\
\hline News & February & 15 & 542 & 11 & 109 \\
& March & 10 & 872 & 1 & 670 \\
Infographic & April & 13 & 2,721 & 17 & 709 \\
& February & 9 & 8,539 & 157 & 2,221 \\
\multirow{5}{*}{ Official Function } & March & 8 & 1,307 & 13 & 341 \\
& April & 7 & 1,344 & 18 & 391 \\
\multirow{5}{*}{ Random Posts } & February & 4 & 628 & 45 & 141 \\
& March & 6 & 334 & 15 & 121 \\
& April & 7 & 328 & 12 & 1,450 \\
& February & 8 & 3,541 & 233 & 271 \\
& March & 5 & 698 & 46 & 210 \\
\hline
\end{tabular}

At this juncture, it seems that KKM's methods of information delivery does not match with followers' preference as the former mainly opts with News post-types, followed with Infographics, Random Posts and Official Function. However, Infographics presents greatest level of share engagement amongst followers followed with Random Posts, News and Official Function. 


\subsection{Information Sharing Motivations (Study B)}

Table 3 portrays the demographic distribution of our questionnaire respondents. There were fiftyone respondents to our questionnaire ranging from the age of 18 to 64 years old. For better readability, the results will be discussed in the context of respondents age as to show the pattern distribution of FB use.

The largest group of respondents came from the Millennials (27 respondents) followed closely with Gen X (20 respondents). The smallest group were the Baby Boomers with only 4 respondents. This user distribution matches with [12] distribution of FB users worldwide. Largely it can be implied that a large portion of KKM followers are between the age of 18 to 52 years old. Table 3 also portrays the respondents as having varying experience in using social media. Five of the respondents are novice users (less than 2 years of experience) while eight of the respondents are highly experienced (11 years of experience). With social networking sites gaining popularity in the early 2000 s, it is rather surprising to see that the large portion of respondents only had 5 to 7 years of experience in social media use (19 respondents) indicating a delay in 'joining the crowd'. Millennials makes up the largest composition of the user group and with the most of experience, suitably being inferred as well-versed with social networking earning the label $\mathrm{Net}$ Generation [13].

FB was launched in year 2004 making it 13 years of age at time of this paper. It can be perceived from Table 3 that many of the respondents (31 respondents) are early users of FB with them claiming to be a member for over seven years. Three of the respondents are FB novices. This could be a positive outlook as this may suggest that FB is still growing in Malaysia with new users joining in the social networking arena. However, an intervention may be required to capture the interest of the Baby Boomers as they are a very small group and there were no new FB members from this group at the time of study.

Table 3. Respondents Demographic Profile

\begin{tabular}{|c|c|c|c|c|c|c|c|c|c|c|c|c|c|c|c|}
\hline \multirow[t]{2}{*}{ Age Generation* } & \multicolumn{2}{|c|}{ Gender } & \multicolumn{5}{|c|}{ Social Media Experience (years) } & \multicolumn{4}{|c|}{ Facebook Experience (years) } & \multicolumn{4}{|c|}{ Interaction Frequency** } \\
\hline & M & $\mathrm{F}$ & $<2$ & $2-4$ & $5-7$ & $8-10$ & $>11$ & $<1$ & $1-3$ & $4-6$ & $>7$ & VF & $\mathrm{O}$ & $\mathrm{S}$ & $\mathrm{R}$ \\
\hline $\begin{array}{l}\text { Millennials } \\
\text { (age:18-36) }\end{array}$ & 12 & 15 & 3 & 6 & 10 & 4 & 4 & 2 & 5 & 9 & 11 & 1 & 8 & 13 & 5 \\
\hline $\begin{array}{l}\text { Gen X (age: } 37- \\
52)\end{array}$ & 4 & 16 & 1 & 5 & 8 & 3 & 3 & 1 & 6 & 5 & 8 & 1 & 7 & 10 & 2 \\
\hline $\begin{array}{l}\text { Baby Boomers } \\
\text { (age: 53-64) }\end{array}$ & 1 & 3 & 1 & 0 & 1 & 1 & 1 & 0 & 1 & 1 & 2 & 0 & 3 & 0 & 1 \\
\hline
\end{tabular}

* [14] defined Baby Boomers as those born between 1946 to 1964 (53 to 71 years old at the time of this paper). However, we did not receive any response from those over 64 years of age. Also, we set Millennials as 18 to 36 years old instead of 17 to 36 per [14] definition as 18 is the age Malaysians finishes school.

** $V F=$ Very Frequently (Every hour); $O=$ Often (Every 2 to 3 hours); $S=$ Seldom (Few times during day and night); $R=$ Rarely (Log in once a day or in several weeks)

Most of the respondents claimed that they seldom interact with their social media platforms, where they $\log$ in to FB only several times throughout the day. It is also observed that 18 of the respondents often interact with their FB account (every 2 to 3 hours). This indicates that most users do regularly interact with FB but within periodic intervals. Such interaction pace may imply that users do not expect frequent information update. Moreover, FB provide newsfeed feature at users' wall allowing users to be in control of when they consume digital information.

At this point, the results show that users are keen FB users. This indicates that FB is relevant and a probable platform for Malaysian ministries to engage with the netizens particularly with the Millennials and Gen X. However, with Baby Boomers making a very small fraction of the social network community, a mechanism must be put in place to entice them to participate more. The following paragraphs will discuss information preference and information credibility from the view of KKM's followers. To assist readability, the results will also be discussed in the context of respondents age as to better illustrate the patterns of users' sharing motivations.

Figure 1(a) illustrates that Millennials and Gen X prefer Infographics over other types of post. Official Function post-type is the least favoured among all groups of users. This reinforces the findings from Study A. A preference for Infographics may be due to the use of visual components in presenting information [15] aiding in memorability and information engagement [16]. Moreover, Infographics is very suited as an education tool showcasing the relationship between different concepts, processes and summarizing subject of interest [17] which fits nicely into the core objective of KKM as a ministry educating netizens on health and wellbeing. In this respect, the innovation brought by Infographics makes it an appealing information medium. Official Function on the other hand seems more diverted to governmental occasion and do not serve a direct 
importance to the netizens in context of health information. Therefore, KKM may need to revise its information presentation method to match with user preference.

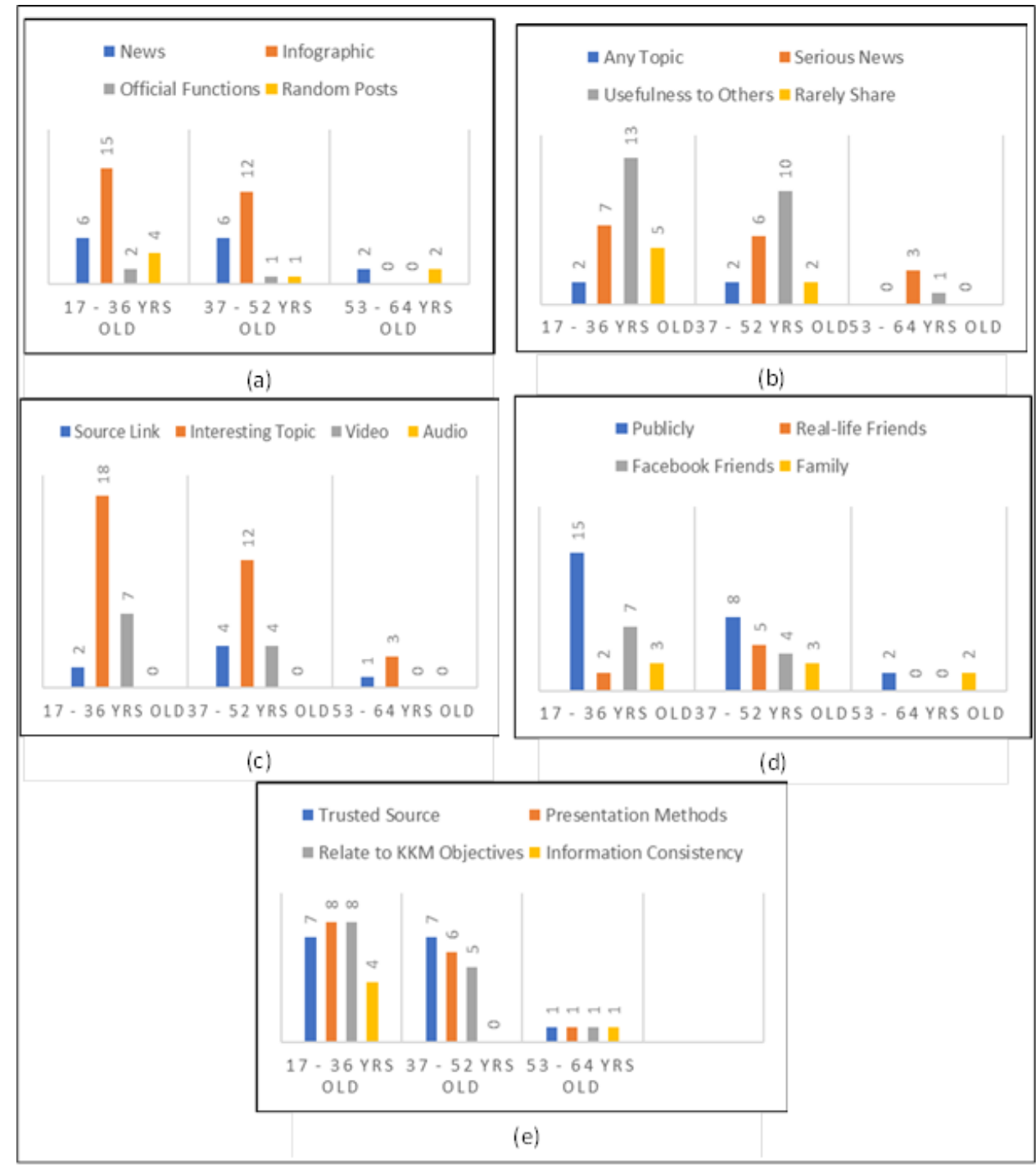

Figure 1. (a) Preferred Information Presentation for Digital Sharing, (b) Sharing Immediateness to Post Content, (c) Information Element that Triggers Digital Sharing, (d) Intended Digital Recipients, (e) Perceived Information Credibility at KKM Facebook Page

Figure 1(b) shows that there are two main motivations for sharing KKM post; (i) the usefulness of information content to others and (ii) it has a serious nuance. This is in line with [18] observation where motivations and content purpose are strongly inter-related. Followers also tend to be selective with the information shared where only a small portion mindlessly share just about any posts from KKM. This may be due to the filtering criteria observed by the users when sharing digital information (see Figure 1 (c)). For example, across all user groups, topics to be shared should be interesting and source link is provided. For Millennials and Gen X, an embedded video to the main content also plays a role. [11] made similar observation where it is suggested that video posts are novel, interesting and worthwhile to share.

When sharing, most of them either share their post publicly or selectively targeted to their FB friends (see Figure $1(\mathrm{~d})$ ). It is rather surprising to note that few of them share with real-life friends or families. However, it could be respondents have assumed friends and family members as part of FB Friends group rather than as an exclusive. The behaviour pattern here indicates that KKM followers are mindful of others and would like to spread information when it brings a greater good. 
Figure 1(e) illustrates why user trust KKM FB page. The reputation of KKM as a trusted source for health and well-being scored highly. Equally important is the methods employed when presenting information at the FB page. Moreover, all information provided relates to the objectives of KKM's ministry indicating that KKM is focused on its information content. This is an important observation as there have been cases of FB pages where they post banters or other information that deviates from the organization's objectives.

The results and discussion have helped shed light to the means of architecting virality. Although this paper intends to look at 'Share' as a form of virality, the degree of share observed in this paper is only twofold (i.e. KKM to KKM followers, and KKM followers to their FB page friends). A more accurate definition of virality would be how much further the information is shared. Nonetheless, this paper has helped point the direction to how government entity could opt in information dissemination to the netizens via FB as evidence show that KKM posts are indeed shared forward by their followers. To make an information viral, a government entity should take information presentation into consideration which includes post-type and information elements available within the post. Evidence have also shown that every post provided by KMM will be shared by the followers but will attain even higher share reaction if the post-type fits with user preference. Perhaps KKM needs to consider utilizing Infographics as the main method in conveying information to the netizens as opposed to the News format currently practiced.

Another limitation of this paper is the scale of the study. We only observed one government ministry FB page and for a short time period. Also, the inability to retrieve Insights data further limits pattern identification. Should the study be carried out longer, with more FB page and combined with Insights data, we could gain insight into a much richer pattern of information design strategy. Future research could clarify if indeed Infographics is the preferred design choice or if the use is merely contextual and dominated by certain user group and FB page. Lastly, as the focus of this paper is on FB as information sharing platform, our findings may not be suitably generalised to other social media platforms. This is because different platform generally serves different purposes calling for different information design strategy.

\section{CONCLUSION}

Our study has identified four types of FB post on a government ministry FB page that are associated with increased or decreased digital information sharing among users. The cross analysis between the FB page observation and user survey concludes that Infographics post-type particularly has higher probability to be shared. However, it is only worth-sharing if it contains other elements that presents itself as credible and has usefulness. Further research is indeed essential, particularly to see how much further the information is shared beyond KKM followers. Also, is there a different information design strategy when other platforms are used (i.e. twitter, Instagram, etc) or do these social media platforms affect each other in terms of information penetration to the netizens. In effect, our study could be used by KKM or other ministries on how they may improve information penetration among the netizens.

\section{ACKNOWLEDGEMENTS}

The authors would like to express the gratitude to the Ministry of Higher Education, Malaysia and Universiti Teknologi MARA, Selangor, Malaysia for the financial support given for this project (BESTARI Grant) [ File No: 600-IRMI/MYRA 5/3/BESTARI (026/2017)].

\section{REFERENCES}

[1] MAMPU (2011). "The Malaysian Public Sector ICT Strategic Plan: Powering Public Sector Digital Transformation". Retrieved $20^{\text {th }}$ January 2016 from http://www.mampu.gov.my/

[2] Kumar, S. T. M. (2017). A Review of Social Media: In Future. Indonesian Journal of Electrical Engineering and Computer Science, 8(1).

[3] Assegaff, S., Kurniabudi, K., \& Hendri, H. (2016). Social Media Success for Knowledge Sharing: Instrument Content Validation. International Journal of Electrical and Computer Engineering, 6(5), 2447.

[4] Berger, J., \& Milkman, K. (2010). Social transmission, emotion, and the virality of online content. Wharton research paper, 106.

[5] Harvard Business Review (2015) "Why Some Videos Go Viral”, Retrieved from https://hbr.org/2015/09/why-somevideos-go-vira

[6] Sampson, T. D. (2012). Virality: Contagion theory in the age of networks. U of Minnesota Press.

[7] Jenkins, H., Ford, S., \& Green, J. (2013). Spreadable media: Creating value and meaning in a networked culture. NYU press. 
[8] Ahmed, S. M., Alruways, F. A., Alsallum, T. F., Almutairi, M. M., Al-Subhi, A. S., \& Ababdulkarim, A. A. (2017). Opinion of Healthcare Professionals in the Usage of Social Media for Patient Care in Majmaah, Saudi Arabia. International Journal of Public Health Science (IJPHS), 6(1), 13-20.

[9] Gottfired, J and Shearer, E. (2016) News Use Across Social Media Platforms 2016. Retrieved June 2016 from Pew Research Center: http://www.journalism.org/2016/05/26/news-use-across-social-media-platforms-2016/

[10] Socialbakers (2017). Facebook stats in Malaysia - Governmental. Retrieved January 2017 from Socialbakers: https://117f8628.socialbakers.com/statistics/facebook/pages/total/ malaysia/society/governmental/

[11] Kite, J., Foley, B. C., Grunseit, A. C., \& Freeman, B. (2016). Please like me: Facebook and public health communication. PloS one, 11(9), e0162765.

[12] Statista (2017). Distribution of Facebook Users Worldwide. Retrieved May 2017 from Statista: https://www.statista.com/statistics/376128/facebook-global-user-age-distribution/

[13] Leung, L. (2013). Generational differences in content generation in social media: The roles of the gratifications sought and of narcissism. Computers in Human Behavior, 29(3), 997-1006.

[14] Reeves, T. C., \& Oh, E. (2008). Generational differences. Handbook of research on educational communications and technology, 3, 295-303.

[15] Dick, M. (2014). Interactive infographics and news values. Digital Journalism, 2(4), 490-506.

[16] Harrison, L., Reinecke, K., \& Chang, R. (2015, April). Infographic aesthetics: Designing for the first impression. In Proceedings of the 33rd Annual ACM Conference on Human Factors in Computing Systems (pp. 1187-1190). ACM.

[17] Meeusah, N., \& Tangkijviwat, U. (2013). Effect of data set and hue on a content understanding of infographic.

[18] Oh, S., \& Syn, S. Y. (2015). Motivations for sharing information and social support in social media: A comparative analysis of Facebook, Twitter, Delicious, YouTube, and Flickr. Journal of the Association for Information Science and Technology, 66(10), 2045-2060. 